\title{
INCLUSÃO E PROCESSOS DE ESCOLARIZAÇÃO: NARRATIVAS DE SURDOS SOBRE ESTRATÉGIAS PEDAGÓGICAS DOCENTES ${ }^{1}$
}

\author{
Carine Mendes da Silva ${ }^{2}$ \\ Daniele Nunes Henrique e Silva \\ Renata Carolina da Silva \\ Universidade de Brasília, Brasilia-DF, Brasil
}

\begin{abstract}
RESUMO. O que dizem os alunos surdos sobre as estratégias pedagógicas empregadas ao longo de sua escolarização? Quais docentes marcaram sua trajetória escolar? Por quê? Estas foram as indagações que nortearam a presente investigação, metodologicamente organizada no formato de entrevista semiestruturada. Nela foram entrevistados seis alunos do Ensino Médio de uma escola pública do Distrito Federal. Na análise dos relatos foram identificadas as estratégias pedagógicas docentes (positivas e negativas) vivenciadas pelos participantes, bem como as expectativas dos estudantes com relação aos seus processos de escolarização. Reafirma-se, na conclusão da análise, a centralidade da Libras para a aprendizagem dos surdos e o uso de recursos imagéticos como estratégia pedagógica fundamental para o êxito acadêmico desse alunado. Outros desdobramentos interessantes foram o papel de instrutores e professores surdos na escolarização e a urgência de se criarem políticas educacionais que viabilizem uma escola de surdos, para surdos e com surdos.
\end{abstract}

Palavras-chave: Surdo; bilinguismo; inclusão escolar.

\section{INCLUSION AND SCHOOLING PROCESS: NARRATIVES OF DEAF STUDENTS ABOUT TEACHERS PEDAGOGICAL STRATEGIES}

\begin{abstract}
What do deaf students say about pedagogical strategies employed throughout his schooling? What teachers marked their school history? Why? These were the questions that guided this research, methodologically organized in semi structured interviews with six high school students in a public school on the Federal District (Brasília). When analyzing the reports we could identify the instructional strategies teachers (positive and negative) experienced by participants as well as the expectations of students regarding their schooling processes. It is reiterated at the conclusion of the analysis, the centrality of Brazilian Sign Language for the deaf learning and the use of pictorial resources as a key teaching strategy to the academic success of these students. Other interesting developments relate to the role of deaf trainers and teachers in education and the urgency of creating educational policies that support a school for the deaf, directed and designed for the deaf.
\end{abstract}

Keywords: Deaf; bilingualism; school inclusion.

\section{INCLUSIÓN Y PROCESOS DE ESCOLARIZACIÓN: NARRATIVAS DE SORDOS SOBRE LAS ESTRATEGIAS PEDAGÓGICAS DOCENTES}

RESUMEN. ¿Qué dicen los alumnos sordos acerca de las estrategias pedagógicas utilizadas a lo largo de su escolarización? ¿Qué tipo de docentes marcaron sus trayectorias escolares? ¿Por qué? Estas fueron algunas de las indagaciones que orientaron esta investigación, metodológicamente organizada en formato de entrevistas semiestructuradas, realizadas con seis alumnos de la Enseñanza Secundaria de una escuela pública, del Distrito Federal (Brasília). En el análisis de los relatos se identifican las estrategias pedagógicas docentes (positivas y negativas) vividas por los participantes, así como las expectativas de los estudiantes con relación a los procesos de escolarización. Se reafirma, en la conclusión del análisis, la centralidad de la LIBRAS (Lengua Brasileña de Señas) para el aprendizaje de personas sordas y el uso de recursos basados en la imagen como estrategia pedagógica fundamental al éxito académico de estos alumnos. Otras derivaciones interesantes se refieren al rol de instructores y profesores sordos en la

1 Apoio e financiamento: Conselho Nacional de Desenvolvimento Científico e Tecnológico (CNPq).

2 Endereço para correspondência: SQN 113, bloco H, ap. 309, Asa Norte, CEP 70.763-080, Brasília DF, Brasil.

E-mail: carine_gnt@hotmail.com 
escolarización, así como la urgencia de crear políticas educacionales que hagan viables escuelas de sordos, para sordos y con sordos.

Palabras-clave: Sordo; bilingüismo; inclusión escolar.

Um dos temas mais debatidos no âmbito educacional é a atual política nacional de educação inclusiva (MEC, 2008). A inclusão educacional apregoa a obrigatoriedade de as escolas públicas oferecerem educação de qualidade para todos os estudantes, respeitando a diversidade de cada um deles eles (Sant'Ana, 2005). Este preceito é tido como um discurso de solidariedade, mas muitas vezes é contraditório, pois não delimita caminhos para a superação da exclusão que ainda assola o cenário escolar (Gomes, 2010).

No tocante a essa questão, Quadros (2003) aponta discordâncias na estruturação das políticas de educação inclusiva no Brasil. A crítica tecida pela autora indica a falta de direcionamento das ações públicas no que se refere a uma discussão mais adensada sobre a inserção dos alunos com necessidades educacionais especiais em turmas regulares, pois as diferenças culturais, linguísticas e de outras ordens apresentadas pelos discentes não são consideradas como prioritárias.

Neste aspecto, a experiência de estudantes surdos merece atenção. Esse é um público cujo desenvolvimento apresenta características singulares, em razão de sua condição linguística e cultural. O sujeito que não ouve é impedido de aprender espontaneamente a língua oral, utilizada pelos ouvintes. No caso dos surdos, a experiência com a língua depende de um canal distinto que privilegie experiências gestuais e visuais (Kelman, Silva, Amorim, Monteiro \& Azevedo, 2011). O desenvolvimento do surdo necessita da língua de sinais, pois ela é a língua dos surdos e por isso mesmo fundamental para inseri-los em processos dialógicos correntes no meio em que vivem, permitindo a sua construção identitária (Lacerda, 2006).

Ciente da essencialidade da Língua Brasileira de Sinais/Libras, autores da área da surdez (Lodi \& Lacerda, 2009; Slomski, 2010), líderes de movimentos surdos, profissionais da Educação e a população surda advogam a necessidade de um modelo educacional que conceba a centralidade dessa língua nas práticas educacionais. Além disso, esses atores têm chamado a atenção para dinâmicas pedagógicas, estratégias curriculares e didáticas estruturadas numa vertente bilíngue.

Sacks (2010) salienta que modelos educacionais para surdos foram oriundos da dicotomia entre o uso ou não da língua de sinais, somados a outros elementos referentes à cultura surda. Daí resultaram formas distintas de compreender a Educação para essa comunidade linguística.

Atualmente, após anos de ênfases oralistas predominam projetos bilíngues na educação de surdos, em que a inclusão social e educacional desses alunos parte do respeito à sua condição bilíngue e bicultural viabilizada pela prioridade da Libras nos processos de ensino-aprendizagem (Ribeiro, 2013). Essa premissa tem consolidado espaços menos árduos para a aquisição do português como segunda língua. É preciso ressaltar que as ênfases oralistas referidas acima, dizem respeito à filosofia educacional que visa à reabilitação do surdo, condicionando a aprendizagem ao desenvolvimento da língua oral e usando métodos ancorados na leitura orofacial (Slomski, 2011).

Não obstante, a forma como a proposta bilíngue se estrutura na prática educacional ainda é um desafio. Não existe consenso interpretativo sobre o que é o bilinguismo e como essa proposta se define nas práticas pedagógicas (Ribeiro, 2014). Atualmente coexistem diferentes modelos para a educação bilíngue dos surdos (Lebedeff, 2010), por isso é importante evidenciar como as ações orientadas pela ótica bilíngue têm sido sistematizadas no cotidiano dos estudantes.

\section{EDUCAÇÃO BILÍNGUE PARA SURDOS E VIDA NA ESCOLA}

Como dito anteriormente, considerado como uma proposta filosófica de educação para os surdos, o bilinguismo apresenta-se de forma crescente no cenário educacional nacional. Ele é responsável por transformações da concepção ideológica sobre a surdez e uma revolução na organização do processo de inclusão escolar, pois evidencia a centralidade da língua de sinais 
no processo de escolarização do surdo (Fernandes \& Moreira, 2009).

De fato, a língua tem um papel central na formação do funcionamento psicológico superior - portanto, também na atividade consciente do homem. Para Vigotski (1991), autor de referência de vários estudos sobre a surdez, a palavra é a "unidade que reflete de forma mais simples a unidade do pensamento e da linguagem" (p. 398); ou seja, é "... uma unidade indecomponível de ambos os processos" (Vigotski, 1991, p. 398). Neste sentido, a inclusão educacional do surdo está diretamente relacionada com a presença e promoção da língua de sinais na escola. Por outro lado, assumir esse princípio é um desafio pedagógico.

Diante desses pressupostos, o trabalho do professor é frequentemente priorizado pelos pesquisadores da área (Razuck, 2011; Silva, 2010). Além do papel docente, Quadros (2006) descreve a importância de garantir, já no momento da matrícula, a presença de intérpretes para o encaminhamento da escolarização dos surdos; mas Lacerda (2006) observa que a presença do intérprete dissociada de uma circularidade da língua de sinais no interior da escola não garante uma efetiva inclusão dos surdos. Muitas vezes, eles não estabelecem relações sociais efetivas, pois seus professores, os companheiros de classe e os funcionários são ouvintes.

O tratamento dos aspectos pedagógicos tem sido reiteradamente discutido nos estudos concernentes ao bilinguismo, contribuindo para a reflexão e proposição de novos caminhos para a educação dos surdos. O papel do professor e do intérprete, os modos de promover a língua de sinais na escola e o desenvolvimento de metodologias específicas para a aprendizagem dos surdos são aspectos sinalizados em recentes esforços investigativos (Ribeiro, 2014), porém não há uma diretriz ou um modelo já consolidado de como deva ser a educação de surdos, e neste sentido, a sensação dos professores, de acordo com Santos (2011), é de limitações na formação para o atendimento desse alunado diante de sua peculiaridade linguística.

$\mathrm{Na}$ busca de uma mudança de foco na investigação, parece-nos importante entender o que os surdos pensam sobre os processos de escolarização vivenciados em suas trajetórias acadêmicas. Em sintonia com a necessidade de preencher essa lacuna, problematizamos neste artigo as estratégias de ensino utilizadas para a aprendizagem do surdo, tendo como referencial a percepção dos estudantes sobre a sua vida na escola. Buscamos evidenciar, pela voz dos surdos entrevistados, as práticas pedagógicas vivenciadas e os modos de configuração da atuação docente.

Os relatos identificam a condução docente das atividades de sala de aula e o diferencial (reconhecido pelo surdo) dos professores considerados bons, em contraponto às dinâmicas e posturas pedagógicas consideradas negativas. Neste sentido, o objetivo da pesquisa é identificar o que os surdos dizem sobre seus professores ao analisarem determinadas peculiaridades das práticas pedagógicas docentes e as estratégias que privilegiaram (ou não) seus processos de aprendizagem.

\section{DELIMITAÇÃO DO ESTUDO}

Pesquisas recentes (Machado, 2006; Silva \& Abreu, 2012; entre outros) têm exposto relatos de surdos que anseiam por uma educação mais próxima da proposta bilíngue, evidenciando reflexões acerca da escola que os surdos querem. Tais reflexões estão baseadas no documento resultante de um evento que antecedeu o $\mathrm{V}$ Congresso Latino-Americano de Educação Bilíngue para Surdos: "A Educação que nós, surdos, queremos". Este é um documento elaborado pela comunidade surda no período entre o Pré-Congresso ao $\mathrm{V}$ Congresso Latino-Americano de Educação Bilíngue para Surdos, em Porto Alegre-RS, em 1999.

$\mathrm{Na}$ ocasião, líderes de movimentos surdos e educadores reuniram-se com o objetivo de ampliar o debate em torno dos seguintes temas: identidades surdas, cultura surda e educação de surdos. Esse evento foi realizado somente por pessoas surdas e se constituiu como uma ação política que buscava dar visibilidade e autonomia à comunidade para tomar decisões no que tange à cultura, à filosofia educacional e à língua de sinais (Thoma \& Klein, 2010).

Essa ação política demonstrou os esforços dos defensores dos direitos dos surdos e da comunidade para indicar a necessidade de criar escolas exclusivas para surdos - uma escola orientada a promover um lugar de encontro para o desenvolvimento da identidade surda e a articulação dos processos educacionais comuns a essa minoria linguística. 
Ainda nesse campo investigativo, Quadros \& Perlin (2007) organizaram uma coletânea de textos denominada Estudos Surdos II, em que os autores discutem desde a história da educação dos surdos até as questões relacionadas ao impacto cultural vivenciado por esses sujeitos. Essa série de pesquisas apresenta diversos relatos referentes às dinâmicas educacionais que revelam o olhar do surdo como aluno, professor, sujeito de pesquisa e, principalmente, como autor de sua trajetória.

Campello (2007), por exemplo, descreveu o trabalho de uma professora surda que se beneficiava da pedagogia visual nos processos de ensino-aprendizagem, traduzindo, de forma geral, a importância de uma reformulação curricular e de uma didática que explorasse não apenas a imagem, mas uma "semiótica visual na prática educacional cotidiana" (Campello, 2007, p. 130). A investigação de Campello (2007) foi resultante do projeto "Educação de Surdos: professores surdos, professores bilíngues e intérpretes de línguas de sinais" (2003-2008), desenvolvido pela Universidade Federal de Santa Catarina.

Outro estudo recente que deu visibilidade às narrativas de surdos adultos sobre processos de escolarização foi apresentado no Encontro Nacional de Didática e Práticas de Ensino (ENDIPE, 2012). Silva \& Abreu (2012) focalizaram um grupo de atendimento psicoeducacional para surdos adultos que integrava 0 projeto Surdez e Sofrimento Psíquico, desenvolvido no Centro de Atendimento e Estudos Psicológicos (CAEP), do Instituto de Psicologia da Universidade de Brasília. Tal grupo reuniu psicólogos, pedagogos, intérpretes de língua de sinais e profissionais de áreas afins com o objetivo de dar atenção aos surdos, visando à melhoria de sua qualidade de vida a partir da compreensão de sua condição bicultural. Em sessões realizadas com um grupo de cinco surdos durante dois anos, foram analisadas as narrativas sobre suas experiências escolares. Os surdos pesquisados narraram que as escolas oralistas, geralmente escolhidas por seus pais (ouvintes), deixaram marcas negativas em suas trajetórias acadêmicas e que a proibição do uso de sinais e a ideia de que o não ouvir era um sinônimo de deficiência trouxeram prejuízos acadêmicos objetivos, como reprovação e desinteresse pela escola e uma limitação perceptiva de sua condição bicultural.
Apesar do empenho dos pesquisadores supracitados em analisar a vida na escola a partir das narrativas dos próprios surdos, permanece a falta de investigação sobre forma como se materializam as propostas bilíngues em termos de estratégias pedagógicas. Neste contexto, o presente estudo procurou identificar - que dizem os alunos surdos sobre as estratégias pedagógicas empregadas ao longo de sua escolarização, quais docentes marcaram suas trajetórias escolares e por que isto se deu.

\section{MÉTODO}

O contexto de investigação foi um centro de Ensino Médio da rede pública do Distrito Federal, que possui aproximadamente quarenta alunos surdos matriculados. Os participantes da pesquisa foram seis estudantes surdos, entrevistados por duas pesquisadoras e uma intérprete.

É importante sinalizar que todos os requisitos exigidos pelo Comitê de Ética do Instituto de Ciências Humanas da Universidade de Brasília foram acatados. Cumpre salientar que a tradução é um importante elemento a ser considerado na construção de dados. Sabe-se que a atuação do intérprete acontece em um espaço transitório entre duas línguas, constituídas por modalidades de comunicação distintas (Quadros, 2006). Na tradução da língua falada para a língua de sinais e vice-versa, o intérprete seguiu o estabelecido no Código de Ética, o qual estabelece uma prática que preconiza a veracidade e o sigilo das informações, fatores fundamentais para a confidencialidade da investigação.

\section{Sujeitos de pesquisa}

Os surdos participantes da pesquisa eram alunos do terceiro ano do Ensino Médio matriculados em uma escola da rede pública do Distrito Federal. São eles (nomes fictícios): a) Fernanda, 18 anos, com surdez congênita severa no ouvido esquerdo e profunda no ouvido direito; b) Raquel, 17 anos, com surdez leve no ouvido esquerdo e moderada no ouvido direito; c) Pablo, 18 anos, com surdez congênita bilateral severa; d) Carol, 20 anos, com surdez severa no ouvido direito e profunda no ouvido esquerdo; e) Bruna, 19 anos, com surdez congênita severa no ouvido direito e profunda no ouvido esquerdo; e 
f) Luís, 18 anos, com surdez severa no ouvido direito e profunda no ouvido esquerdo.

Quando perguntaram aos participantes qual a forma de comunicação que adotavam mais comumente, as pesquisadoras obtiveram as seguintes informações: Bruna usava, principalmente, a língua de sinais e, ocasionalmente, a língua oral; Carol se comunicava exclusivamente em Libras; Luís usava ambas as línguas, a depender do contexto social e comunicativo, mas tinha muita dificuldade em se fazer entender com a linguagem oral; Fernanda, Raquel e Pablo comunicavam-se por meio da língua oral e utilizavam a Libras na escola. Cumpre referir que Raquel, apesar de um bom resíduo auditivo e certa facilidade em compreender a língua oral, dizia-se surda e se comunicava preferencialmente por meio da língua de sinais, e também participava ativamente da sala de recursos e dizia ter muita dificuldade para escutar e entender o professor no contexto da sala de aula inclusiva, sem a presença do intérprete.

\section{Considerações sobre a coleta e a análise dos dados}

O trabalho de campo foi desenvolvido a partir de duas entrevistas realizadas individualmente com os sujeitos da pesquisa. Tais entrevistas foram videogravadas no primeiro semestre de 2013, tendo a duração de aproximadamente 100 minutos cada. $\mathrm{Na}$ primeira entrevista com os estudantes, as pesquisadoras explicaram as questões que orientaram a investigação (aspectos gerais da trajetória escolar dos surdos) e registraram em ficha de identificação informações referentes aos participantes e esclarecimentos sobre o tratamento ético do trabalho, incluindo a assinatura do Termo de Consentimento Livre e Esclarecido (TCLE). Na segunda entrevista foram discutidas questões orientadas em três blocos: 1- Concepção do estudante sobre seu processo de escolarização; 2- As experiências escolares nas séries iniciais; e 3- Memórias acerca do trabalho docente em sala de aula.

$\mathrm{Na}$ organização dos dados coletados, decidimos traduzir (com o apoio da intérprete) e transcrever integralmente todas as entrevistas videogravadas. Em seguida, após esse primeiro esforço de organização do material, identificamos eixos categoriais para análise.
A seguir serão apresentados três eixos de análise desdobrados dos dados coletados: 1Identificação das estratégias pedagógicas docentes positivas; 2- Identificação das estratégias pedagógicas docentes negativas; e 3- As expectativas e críticas dos estudantes surdos com relação ao processo de escolarização.

\section{RESULTADO E DISCUSSÃO DOS DADOS}

A análise e a discussão dos dados transcritos foram realizadas considerando-se os objetivos propostos na pesquisa. Os depoimentos apresentam as narrativas dos surdos sobre suas memórias escolares, com ênfase na análise das práticas docentes em salas de aula inclusivas.

Ao serem questionados sobre a metodologia de ensino vivenciada e seus antigos professores, os alunos por vezes remetem-se aos momentos de atuação do intérprete, sendo necessário reconduzi-los ao foco do estudo, ou seja, às práticas docentes; contudo, ao longo das entrevistas, quando reconduzidos aos objetivos propostos da pesquisa, os estudantes evidenciam as estratégias pedagógicas que se apoiam (ou não) em recursos expressivos.

\section{Eixo de análise 1: A Identificação das estratégias pedagógicas docentes positivas}

As memórias escolares positivas dos surdos pesquisados fazem referência às experiências que privilegiam a transposição do conhecimento por meio de imagem e da repetição do conteúdo. Pablo, por exemplo, lembra, a respeito de sua professora de português da sétima série:

Ela me explicava através de figuras. Ela escrevia frases, mandava eu repetir aquela frase. Aí, mandava eu escrever aquela frase. Ela me perguntava o que eu não entendi nessa frase.... Eu preciso entender aquilo pra poder fazer! $O$ professor vai ficar repetindo mil vezes até chegar em um ponto que o aluno entendeu.

$\mathrm{Na}$ mesma linha, Bruna aponta que a repetição articulada ao uso de desenho era uma estratégia pedagógica eficiente utilizada por seu professor de Biologia do primeiro ano do Ensino Médio: "Foi desenho, foi escrita, foi livro, revista. As explicações também. Não tinha intérprete. Aí, 
ele desenhava, colocava o nome, usava o data show... Ele explicava mais vezes para que os surdos conseguissem pegar, acompanhar."

Além das explicações repetidas, Luís, assim como Bruna, destaca o papel dos recursos imagéticos. Ele comenta sobre o atual professor de Geografia do $3^{\circ}$ ano do Ensino Médio: "Ele usa livros, escreve, usa mapa. Ele desenha, usa fotos de acontecimentos!"

Cumpre ressaltar que, para os surdos investigados, os recursos pedagógicos imagéticos e/ou a repetição precisam do apoio do intérprete para serem amplamente explorados. De fato, a atuação do intérprete na sala de aula apareceu repetidas vezes nos comentários dos alunos como aspecto fundamental para o processo de inclusão educacional dos surdos, pois é ele quem traduz os conteúdos. O relato de Carol evidencia esse aspecto: "Se não tem o intérprete, eu não consigo entender muita coisa. Se o professor escrever... aí, eu tento me forçar um pouco mais.... Agora, se ele só falar... não...."

Raquel, apesar de ter um bom resíduo auditivo e se comunicar com certa facilidade pela oralidade, tinha muitas dificuldades em compreender o professor sem o apoio do intérprete. Seus relatos se coadunam com os aspectos apontados por Carol e sugerem que o intérprete oferecia um apoio importante para Raquel, permitindo-lhe entender melhor aquilo que estava sendo oralizado pelos docentes. De fato, Raquel, quando apoiada só na oralidade, somente captava partes isoladas e descontextualizadas da informação que estava sendo transmitida pelos professores, enquanto com o intérprete é diferente. Ela relata: "Com a intérprete na sala de aula dá pra eu perguntar e entender o que ela (a professora) tá explicando.... Aí, já fica melhor!"

Fernanda, por exemplo, lembra-se de uma situação com o professor de Biologia do primeiro ano do Ensino Médio: ele perguntou à aluna qual a metodologia que ela gostaria que fosse utilizada em sala de aula:

\footnotetext{
Aí, eu falei (para ele): 'Melhor desenho e mostrando porque é visual. Se ficar só escrevendo, eu não vou entender muito bem. Então, é melhor desenho pra eu entender melhor'. Eu me sentia ótima, porque eu entendia, mas mesmo assim eu acreditava que precisava da intérprete!
}

De acordo com Campello (2007), na sociedade contemporânea a imagem assume um papel tão importante quanto o dos discursos verbais na aquisição de conhecimento. Por isso é indispensável que as escolas trabalhem metodologias e didáticas que explorem o pensamento crítico sobre a imagem, incentivando a interpretação dos recursos visuais e extrapolando as práticas tradicionais, calcadas exclusivamente na oralidade e escrita.

Sem dúvida, como afirma a pesquisadora, ainda é incipiente o reconhecimento dos recursos visuais como linguagens não verbais, cujos suportes vão desde a tela do computador até o próprio corpo (Campello, 2007). Essas linguagens anunciam grandes contribuições para a educação de surdos, embora estudos na área da pedagogia visual ainda sejam escassos, o que implica a falta de direcionamento do trabalho docente sob esse enfoque.

A utilização de recursos visuais, especialmente das imagens, é destacada em vários depoimentos como ferramenta pedagógica positiva na educação dos surdos. Buzar (2009) evidencia essa questão quando identifica a singularidade visuoespacial do sujeito surdo. A autora destaca que aqueles que não ouvem percorrem outro caminho para se expressar e se comunicar com o mundo. Desse modo, as práticas que privilegiam a visualidade demonstram ser elemento importante no trabalho em sala de aula com os surdos.

Nessa linha, Lebedeff (2010) também enfatiza a carência de práticas que oportunizem a leitura e compreensão do mundo a partir da visão. Para ela, o surdo necessita de um letramento visual, uma proposta pedagógica específica. Esse pensamento coaduna-se com a ideia de que somente é possível compreender o sujeito surdo quando se aceita que sua fonte de comunicação é visual, e não auditiva, o que é uma especificidade à qual o trabalho pedagógico não deve ficar alheio. Não obstante, a pesquisadora ressalta que é justamente por essa condição ser frequentemente desrespeitada em ambientes escolares que existem altíssimos índices de fracasso e evasão desse alunado.

Embora os relatos evidenciem a essencialidade do uso de recursos visuais em sala de aula, eles não são suficientes para que a barreira da linguagem seja vencida e o trabalho pedagógico seja bem qualificado como um todo. É também é importante a presença do intérprete, pois para entender recursos visuais como 
imagens, vídeos e desenhos o deficiente auditivo necessita da atuação desse profissional. O alcance de resultados positivos pelos discentes ocorre a partir da interseção dos seguintes fatores: reconhecimento da língua de sinais (como a primeira língua do surdo); trabalho baseado na dimensão visuogestual (uso de imagens), e participação do intérprete de Libras (Giordani, 2004).

O intérprete da língua de sinais é uma figura de destaque entre os apoios necessários aos estudantes surdos em contextos inclusivos. A presença desse profissional indica que a condição linguística do surdo é respeitada (Lacerda, 2004), e sua ausência em ambientes educacionais que atendem surdos sugere a ocorrência de uma inclusão apenas física desses sujeitos (Machado, 2006). De fato, muitas instituições educacionais não oferecem nenhum canal de comunicação que oportunize aos surdos a aquisição dos conhecimentos transmitidos na escola. Não há instrutores surdos, nem mesmo intérpretes da língua de sinais.

Quadros (2006) afirma que todo ser humano é capaz de comunicar-se, mas essa capacidade depende das oportunidades de acesso à linguagem e dos meios de interação social que o ambiente ofereça. Isto significa que a língua é um sistema social constituído culturalmente, por isso os alunos surdos requerem, além das ferramentas visuais, um canal de comunicação comum para estabelecerem suas relações no espaço escolar, possibilitando o seu amplo desenvolvimento cognitivo (Perlin, 2006).

Lacerda (2006) traz reflexões importantes sobre o papel do intérprete na sala de aula. Muitos surdos, por exemplo, alegam não compreender boa parte do que é traduzido, mas preferem que o intérprete esteja em sala, pois sua ausência agrava o quadro comunicativo, impedindo a aprendizagem.

\section{Eixo de análise 2: A identificação das estratégias pedagógicas docentes negativas}

Os alunos entrevistados elencam fatores que tornam as atividades escolares ininteligíveis. Como ponto negativo emerge nos relatos, reiteradamente, 0 uso de metodologias que privilegiam a oralidade na sala de aula.

Bruna, ao ser questionada sobre os fatores negativos da postura docente que contribuem para o seu baixo rendimento, recorda-se de seus professores do Ensino Fundamental:
Ciências era muito difícil, eu tinha muita dificuldade. O professor falava demais, falava muito. Eu não entendia nada. Ele falava rápido demais. Ele escrevia pouco, falava muito mais do que escrevia. Matemática também. Às vezes, eu tirava nota baixa, quatro, às vezes. $O$ professor era ruim... porque ele também falava muito. Para os ouvintes era fácil, mas para o surdo era difícil. Não tinha intérprete. Eu só tinha a sala de reforço como um apoio para o ensino das matérias. Mas a matéria em si, dentro da sala de aula, não tinha o intérprete, não tinha ninguém... (O professor) de Filosofia não ensinava bem. Porque ele só falava.

Ressalta-se, na narrativa de Bruna, a ausência do intérprete como algo relacionado à dificuldade de compreender os conteúdos curriculares. Sobre isso, Luís reclama de seu professor de Matemática da quinta série:

Ele explicava muito rápido para os ouvintes, mas eu não conseguia entender. Eu não conseguia aprender matemática.... Quando a intérprete faltava, eu ficava observando bastante o professor. Eu sempre perguntava pra ele as dúvidas.... Mesmo que o professor respondesse, eu continuava com dúvida.

Pablo explica de modo objetivo o problema do ensino baseado exclusivamente na oralidade e relata uma situação vivida no dia da entrevista:

Hoje eu tive ditado. O professor ditou um texto. Imagina os D.A. (deficientes auditivos), como eles vão ver? O professor tem que fazer o quê? Escrever. Aí, o professor nem escreveu. Por quê? O professor não conhece... não conhece o surdo. Ele tá achando que o surdo é igual aos ouvintes.... Esses professores, eles explicam a matéria não escrevendo, eles explicam falando. Aí, igual eu falei... eles falam uma palavra muito "avançada", que não tem em Libras, não existe em Libras... Aí, a intérprete precisa ouvir e traduzir. Esse é o trabalho dela... mas ela não consegue ouvir tudo. Então, ela precisa fazer o quê? Ela precisa ouvir e resumir para o surdo entender melhor. Porque ela não pode traduzir certinho o que o professor falou. Ela vai chegar em um ponto que não tem em Libras... naquela palavra! Aí, ela escuta o professor e tenta resumir para o surdo entender melhor. 
Percebe-se, assim, que alguns professores descritos nas entrevistas planejam suas aulas $e$ avaliações de modo a contemplar somente a maioria ouvinte, delegando a especificidade linguística e visual do surdo para a atuação do intérprete.

Ao narrar as principais dificuldades enfrentadas no convívio com uma nova professora do primeiro ano do Ensino Médio, Fernanda também enfatiza esse aspecto:

Chegou a outra professora.... Aí, a segunda (professora) não aceitava nem um tipo... ficava reclamando: "Ó, isso aqui tá errado!". Ela ficava reclamando e dava desconto de 1 ponto. Eu perdia muito ponto! Teve uma vez, a primeira vez que eu fiz redação na escola (que era valendo 4 pontos), eu perdi 1,5 na prova porque a... professora não aceitava nenhum motivo. Ela queria que eu escrevesse igual a todo mundo.

Ainda hoje o sistema educacional enfrenta obstáculos na implementação de uma proposta bilíngue efetiva. Concepções antigas que fundamentavam a educação dos surdos não são facilmente substituídas, permanecendo práticas somente expositivas nas escolas regulares.

Silva \& Abreu (2012), em concordância com Skliar (2003), afirmam que as diversas compreensões sobre educação de surdos e metodologias bilíngues não têm conseguido desencadear um processo bem-sucedido de inclusão. Eles observam que diversas práticas institucionais denominadas bilíngues ainda têm enraizadas percepções antigas sobre a surdez, baseadas em concepções do modelo clínico, oralista e assistencialista de educação para surdos.

Nesse sentido, Fernanda relata em sua entrevista que, mesmo em escolas inclusivas, vivenciou a obrigação de integrar-se à cultura ouvinte. Era exigida dela, por exemplo, a realização de produções escritas em português em condições semelhantes àquelas elaboradas pelos ouvintes.

Sabemos que, por si só, a surdez não é um obstáculo à aquisição de conhecimento (Quadros, 2006), mas o tratamento destinado ao aluno surdo reflete situações de desrespeito à sua singularidade linguística, resultantes de oportunidades educativas desiguais em relação às oferecidas aos alunos ouvintes. Pablo, em sua fala, sugere que o aluno surdo não tem acesso à mesma quantidade de informações que os ouvintes. Ele comenta: "Ela (a intérprete) não consegue ouvir tudo. Então, ela precisa fazer o quê? Ela precisa ouvir e resumir para o surdo entender melhor." Ou seja, a aprendizagem acessível ao aluno surdo é inferior àquela acessível ao ouvinte.

Lacerda (2004) alerta para as discrepâncias no acesso ao conteúdo entre alunos surdos e ouvintes. De fato, a tradução muitas vezes resume as informações, encurta caminhos. Nesse cenário, o aluno surdo é excluído das discussões e dos comentários secundários que ocorrem durante as aulas. As condições de participação do aluno surdo em uma sala de aula regular diferem qualitativa e quantitativamente daquelas disponíveis ao aluno ouvinte.

\section{Eixo de Análise 3: Expectativas e críticas dos estudantes surdos com relação ao processo de escolarização}

Quanto às expectativas dos alunos sobre o seu processo de escolarização, foi constatada uma consonância de ideias a respeito da importância da língua de sinais nas dinâmicas escolares. $O$ trabalho do intérprete em sala de aula e a presença da comunidade surda na escola foram elementos destacados nos relatos. Raquel, ao relembrar a época em que passou a frequentar, no Ensino Médio, uma instituição de ensino onde havia um número significativo de alunos surdos, narra: "Eu percebi que eu tinha que ficar em uma escola junto com surdos e ouvintes... que, aí, eu consigo entender melhor."

Carol relata: "O ano passado foi o mais legal.... A direção da escola foi trocada! A (atual) diretora sabe língua de sinais. Então, ela dá palestras em alguns lugares e ela faz língua de sinais."

Ao anunciar suas expectativas a respeito da equipe escolar, Carol evidencia o desejo de que essa seja composta por profissionais que conheçam a língua de sinais, por isso é tão importante a diretora conhecer a Libras. Isso significa que a diretora, de certa maneira, está sensível às questões vivenciadas pelos surdos.

Mesmo com o trabalho do intérprete, Fernanda narra as dificuldades que esse profissional encontra para transmitir integralmente as informações passadas pelo professor regente:

O professor vai falando e vai passando no quadro... A intérprete tem que correr com o que o professor fala. Ou seja, 
perde as ideias; pula as principais coisas, as mais importantes que 0 professor fala! O que é melhor?! Uma pessoa falando direto, do que ficar com dois olhando pra lá e pra cá, perde o acompanhamento do que o professor escreve no quadro...

Fernanda sugere, sem anunciar explicitamente, a importância da sala de recursos (local em que os surdos ficam juntos e aprendem com um professor que se comunica exclusivamente em Libras). Pablo explicita:

Os ouvintes pensam: por que o surdo tira nota boa? Porque eles têm a sala de recursos. Agora pensa, se ele não tivesse a sala de recurso, o surdo não ia.... Hoje, um menino de vinte anos estaria na oitava série, no Ensino Fundamental. Mas ele [o professor] percebeu que aqui tem sala de recursos, então, ele deixa os D.A. de lado, para a sala de recursos resolver esse problema....

Bruna segue na mesma argumentação de Pablo, mas chama a atenção para outro aspecto:

A minha vontade é que fosse uma sala só pra surdos. Só pra surdos. É a minha vontade.... Nas outras salas, o que dificulta é a visibilidade do professor e do intérprete, que, às vezes, confunde um pouco.... Aqui (na sala de recursos) os professores são melhores.

O relato de Bruna traduz claramente a insatisfação diante da dificuldade em administrar um conhecimento tratado simultaneamente pelo professor e pelo intérprete na sala de aula. Ela afirma: "A minha vontade é que fosse uma sala só pra surdos. Só pra surdos. É a minha vontade.... Nas outras salas, o que dificulta é a visibilidade do professor e do intérprete, que, às vezes, confunde um pouco".

Bruna acrescenta que a melhor opção para a educação dos surdos parte da composição de classes constituídas apenas de alunos surdos. Essa colocação segue a direção do documento "A Educação que nós surdos queremos" (1999), enfatizando a importância de respeitar a forma visual de apreensão do mundo, estimulando estratégias pedagógicas pautadas no bilinguismo e dá indicativos importantes sobre o papel central do professor/instrutor surdo. Bruna parece sugerir que o intérprete é um paliativo que responde, nem sempre de forma satisfatória, a um determinado modelo de inclusão educacional. Para ela, o ideal é que a escola fosse "uma sala só pra surdos. Só pra surdos. É a minha vontade."

Pablo, por outro lado, evidencia que os professores da sala regular não se responsabilizam pela formação do aluno surdo justamente porque sabem da existência da sala de recursos. Ele comenta: "Mas ele (o professor) percebeu que aqui tem sala de recursos, então, ele deixa os D.A. de lado, para a sala de recursos resolver esse problema."

Quadros (2006) afirma que os professores do ensino regular tendem a transferir a responsabilidade de ensinar aos surdos para os professores da Educação Especial, que são responsáveis pelas salas de recursos. Assim, o aluno surdo é prejudicado por receber uma carga excessiva de aulas. Além disso, não são raras as situações em que o surdo se torna mero copiador dos conteúdos tratados na sala regular. Tal fato provoca descontentamento com as práticas educativas disponíveis para esses sujeitos.

Salientamos que, para os alunos entrevistados, as trocas de conhecimento mais bem qualificadas ocorreram com professores que eram proficientes em Libras, em especial, na sala de recursos. Esse mesmo aspecto foi discutido por Ribeiro (2014) em sua dissertação de mestrado, em que a pesquisadora analisa, a partir dos comentários dos surdos sobre seus processos de escolarização, a importância de os docentes estarem sensíveis às especificidades da língua de sinais e, consequentemente, às necessidades pedagógicas dos surdos. Para a autora, os papéis assumidos na sala regular pelo professor regente e pelo intérprete são contraditórios e tais práticas bidocentes precisam ser questionadas.

\section{CONSIDERAÇÕES FINAIS}

Evidenciamos, neste artigo, a importância de estudos que focalizem o surdo em seus processos de escolarização. A partir das reflexões teóricas sobre o bilinguismo e seus modos de implementação nos espaços escolares, buscamos investigar o que os estudantes surdos narram sobre suas experiências acadêmicas, tendo como foco a recuperação de suas memórias escolares. 
No exercício de lembrar o vivido, os surdos refletiram sobre as estratégias docentes consideradas positivas e negativas para a aquisição de conhecimento. Além disso, formularam críticas aos processos de escolarização a que são submetidos, chamando a atenção para o modo como as salas de recursos dialogam com as atividades realizadas nas salas regulares. A pouca interação entre surdos na sala regular e a não proficiência em Libras dos professores regentes explicam parte das dificuldades que os surdos sentem diante das exigências acadêmicas.

Vale ressaltar que a análise dos relatos dos surdos revelou a essencialidade do uso da Libras para a aquisição de conhecimento. Sem dúvida, o surdo tem um sentimento de impotência quando a língua não está disponível na sala de aula. Por isso, a presença do intérprete é muito importante, embora não isenta de problemas.

Podemos concluir que o acesso à Libras e a presença do intérprete (articulado com o uso de recursos imagéticos) são aspectos essenciais para a aprendizagem dos surdos, segundo as narrativas dos estudantes pesquisados. Tais aspectos precisam ser priorizados na implementação de projetos acadêmicos bilíngues que se comprometam com esse alunado.

Ademais, as narrativas sugerem desdobramentos interessantes sobre o papel de instrutores e professores surdos na escolarização desses sujeitos, bem como a urgência de criação de políticas educacionais que viabilizem uma escola de surdos, para surdos e com surdos.

\section{REFERÊNCIAS}

Buzar, E. A. S. (2009). A singularidadevisuo-espacial do sujeito surdo: implicações educacionais. Dissertação de Mestrado Não-publicada, Faculdade Educação da Universidade de Brasília, Brasília, Brasil.

Campello, A. R. S. (2007). Pedagogia Visual/ Sinal na Educação de Surdos. In R. M. Quadros. \& G. Perlin. Estudos Surdos I/ (pp. 100-131). Petrópolis, RJ: Arara Azul.

Fernandes, S., \& Moreira, L. C. (2009). Desdobramentos politico-pedagógicos do bilinguismo para surdos: reflexões e encaminhamentos. Revista de Educação Especial, 22(34), 225-236.

Giordani, L. F. (2004). Representações culturais da escrita: letramentos e educação de jovens e adultos surdos. In $\mathrm{V}$
Seminário de Pesquisa em Educação da Região Sul. 2004, 5., Anais... Curitiba, Pr: PUCPR, 2004, 1 CD-Rom.

Gomes, C. (2010). O lugar do sujeito na inclusão escolar: percalços e fracassos nas relações de subjetivação. Tese de Doutorado Não-publicada do Programa de PósGraduação em Psicologia do Centro de Ciências da Vida, Pontifícia Universidade Católica, Campinas, São Paulo, Brasil.

Kelman, C. A., Silva, D. N. H., Amorim, A. C.F., Monteiro, R. M. G., \& Azevedo, D. C. (2011). Surdez e família: facetas das relações parentais no cotidiano comunicativo bilíngue. Linhas Críticas, 17(33), 349-365.

Lacerda, C. B. F. (2004). A escola inclusiva para surdos: a situação singular do intérprete de língua de sinais. Contrapontos, 5, 353-367.

Lacerda, C.B.F. (2006). A inclusão escolar de alunos surdos: o que dizem alunos professores e intérpretes sobre esta experiência. Cadernos Cedes, 26(69), 163-184.

Lebedeff, T. B. (2010). A educação dos surdos na região do planalto médio rio-grandense: uma problematização das condições lingüísticas e de escolarização. In Reunião Anual da ANPED, 33., 2010, Caxambu, MG. Anais... Rio de Janeiro: ANPED.

Lodi, A. C. B. \& Lacerda, C. B. F (2009). A inclusão escolar bilíngue de alunos surdos: princípios, breve histórico e perspectivas. In A. C. B. Lodi, \& C. B. F. Lacerda. (Orgs.). Uma escola, duas línguas: letramento em língua portuguesa e língua de sinais nas etapas iniciais de escolarização. Porto Alegre: Mediação.

Machado, P. C. (2006). Integração/inclusão escolar: um olhar do egresso surdo. In R. M. Quadros, \& G. Perlin (Orgs.). Estudos Surdos I (pp. 39-75). Petrópolis, RJ: Arara Azul.

Perlin, G. (2006). A Cultura Surda e os Intérpretes de Língua de Sinais. Revista Educação Temática Digital, 7(2), 136147.

Portaria $\mathrm{n}^{\circ}$ 555/2007, de 7 de janeiro de 2008 (2008). Política Nacional de educação especial na perspectiva da educação inclusiva. Brasília, DF: Ministério da Educação.

Quadros, R. M. (2003). Situando as diferenças implicadas na educação de surdos: inclusoexclusão. Florianópolis: Ponto de Vista.

Quadros, R. M. (2006). Políticas lingüísticas e educação de surdos em Santa Catarina: espaço de negociações. Cadernos Cedes, 26(69), 141-161.

Razuck, R. C. S. R. (2011). A pessoa surda e suas possibilidades no processo de aprendizagem e escolarização. Tese de doutorado, Programa de PósGraduação em Educação da Faculdade de Educação, Universidade de Brasília, Brasília.

Ribeiro, C. B. (2013). Escolarização de surdos e desenvolvimento bicultural: trajetórias escolares de surdos: entre práticas pedagógicas e processos de desenvolvimento bicultural. In Congresso Brasileiro de Psicologia do Desenvolvimento, 9., 2013, João Pessoa, PB. Anais... João Pessoa: ABPD.

Ribeiro, C. B. (2014). Narrativas e procesos de desenvolvimento bicultural: trajetórias escolares de surdos jovens e adultos. Dissertação de Mestrado, Programa de Pós-Graduação em Processos de Desenvolvimento Humano e Saúde, Universidade de Brasília, Brasília. 
Sacks, O. (2010). Vendo vozes: uma viagem ao mundo dos surdos. São Paulo: Companhia das Letras.

Sant'Ana, I. M. (2005). Educação Inclusiva: Concepções de professores e diretores. Psicologia em Estudo, 10(2), 227234.

Santos, K. R. O. R. P. (2011). Formação continuada (em serviço) e necessidades formativas de professores na educação de surdos da rede pública da cidade do Rio de Janeiro. Tese de Doutorado, Programa de Pós-Graduação em Educação, Universidade Metodista de Piracicaba, Piracicaba.

Silva, D. N. H., \& Abreu, F. S. D. (2012). Trajetórias Escolares: narrativas de surdos adultos em ambiente de atendimento psicoeducacional [Resumo]. In Anais: XVI Encontro Nacional de Didática e Prática de Ensino, 1 (p. 25). Campinas: Unicamp.

Silva, R. C. J. (2010). A formação do professor de alunos surdos. Dissertação de Mestrado, Programa de PósGraduação em Educação da Faculdade de Educação, Universidade de Brasília, Brasília.
Skliar, C. (2003) Perspectivas políticas e pedagógicas da educação bilíngüe para surdos. Campinas: Mercado das Letras.

Slomski, V. G. (2010). Educação Bilíngue para surdos: concepções e implicações práticas. Curitiba-PR: Juruá.

Thoma, A. S., \& Klein, M. (2010). Experiências educacionais, movimentos e lutas surdas como condições de possibilidade para uma educação de surdos no Brasil. Cadernos de Educação, (36), 107-131.

Vigotski, L. S. (1991). A construção do pensamento e da linguagem. São Paulo: Martins Fontes.

Recebido em 23/10/2013

Aceito em 24/04/2014

Carine Mendes da Silva: pedagoga pela Universidade de Brasília, mestranda no Programa de Pós-Graduação em Processos de Desenvolvimento Humano e Saúde, do Departamento de Psicologia Escolar e do Desenvolvimento, do Instituto de Psicologia da Universidade de Brasília, Brasil.

Daniele Nunes Henrique e Silva: doutora em Educação pela Universidade Estadual de Campinas e professora do Instituto de Psicologia da Universidade de Brasília, Brasil.

Renata Carolina da Silva: graduanda em Pedagogia pela Universidade de Brasilia e bolsista do Programa Institucional de Bolsas de Iniciação Científica (PIBIC).. 